\title{
Digital Image Comparisons for Investigating Aging Effects and Artificial Modifications Using Image Analysis Software
}

\author{
Yeongsik Yoo', Woo Sik Yoo ${ }^{2,3,},{ }^{*}$ \\ ${ }^{1}$ College of Liberal Arts, Dankook University, Yongin 16890, Korea \\ ${ }^{2}$ WaferMasters, Inc., Dublin, CA 94568, U.S.A. \\ ${ }^{3}$ Institute of Humanities Studies, Kyungpook National University, Daegu 41566, Korea
}

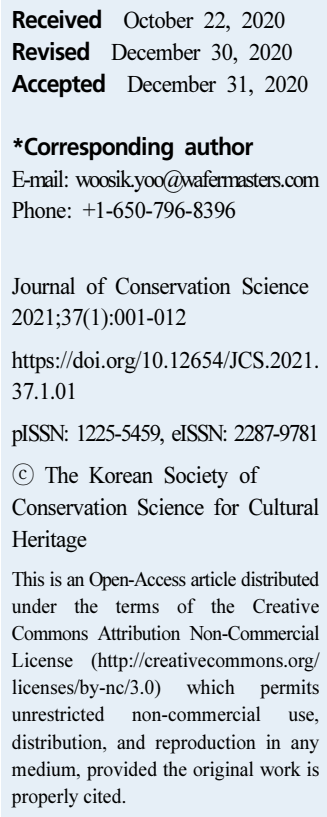

ABSTRACT In the digital era, large archives of information and Internet accessibility make information search, including image search, easier and affordable, even from remote locations. Information transmission and sharing can be performed instantly, at any moment. In the case of images, there are risks of transmitting and recklessly sharing intentionally modified images. Such modified images can also be transmitted and used as an additional source of information by followers. In this study, historical portraits of Yu Kil-Chun are shown, who was the first Korean student to study in both Japan and the United States. He was an intellectual, writer, politician, and independence activist of Korea's late Joseon Dynasty. Using image processing software, the portrait images were compared to investigate aging effects and artificial modifications. Statistics of red (R), green $(\mathrm{G})$, blue $(B)$, and $\mathrm{L}^{*}, \mathrm{a}^{*}$, and $b^{*}$ values of every pixel in the selected identical areas of the portraits were compared to identify possible causes of variations, including aging effects and artificial modifications. Sepia toning, used in black and white photographs until the 1930s, and modern digital sepia toning can be very confusing owing to their aging effects. The importance of preservation of physical copies and preservation of context (interconnections between data and between documents) is discussed from archiving and conservation science perspectives.

Key Words Image comparisons, Aging effect, Sepia toning, Natural change, Artificial modification, Image analysis statistics, Image analysis software

\section{INTRODUCTION}

An archive is defined as "a place in which public records or historical materials (such as documents) are preserved" and "a repository or collection especially of information" (Merriam-Webster, 2020). Van Garderen defined "archival materials are information objects that serve as evidence of past events" (Van Garderen, 2007). He further explains that the archives act as a memory aid or as a proxy for those events by recording information about them, which can be recalled at some point in the future. Archival materials are used to re-experience these events or to re-communicate information about them. The archival materials themselves are not memories; instead, they aid in the recall of past experiences or communications. As noted by Angelika Menne-Haritz, "Archives do not store memory. However, they offer the possibility of creating memory. Their function is that of amnesia prevention" (Menne-Haritz, 2001). Archival materials can only act as a memory aid for a person that was present or participating in the past event by providing information that allows them to remember the event. If the person was not present, archival materials can act as a proxy for the event by communicating information that allows the person to experience specific details or characteristics about 
the event.

Historical documents and objects that provide evidence of the past have been digitized and made available online; in this sense, a digital archive is similar in purpose to a physical archive. If the historical documents were not created digitally in the first place, digital archives were generated via scanning or photography. Digital archives are usually created with the goal of preserving historical objects and making them available to researchers (Sam Houston State Library). Digital archives can be used for the restoration of a physical archive and conservation environment study by monitoring the conditions of physical archives on a regular basis. Physical archives can be a cultural heritage of various forms

In library and archival science, digital preservation is a formal endeavor to ensure that digital information of continuing value remains accessible and usable (Digital Preservation Coalition, 2008). The goal of digital preservation is the accurate rendering of authenticated content over time (Evans and Carter, 2008). Digital preservation also faces both great technical and economic challenges due to the continuing evolution of technology and sustainability of organizations (Wikipedia, 2020f).

In this paper, we compared more than 100-year-old historic photographs available from various digital archives using image analysis software for their statistical colorimetric and dimensional analysis. Digital images of photographs taken in the late $19^{\text {th }}$ century were downloaded from various websites and compared from the viewpoints of data integrity, file fixity, characterization, sustainability, and renderability in conservation science applications. The importance of preserving physical copies and preserving the context through a few examples of historical photographs is discussed from archiving and conservation science perspectives.

\section{MATERIALS AND METHODS}

As we are going to select specific historic photographic images for statistical colorimetric and dimensional analysis, reviewing the history of photography in East Asia first and subsequently the selection of specific digital photographic images and their downloaded source is beneficial. The features of the image analysis software used herein are described below.

\subsection{Brief history of photography in East Asia}

An English photographer, Frederick Scott Archer, published his wet plate collodion process in the March issue of The Chemist in 1851 (Wikipedia, 2020a). It became the most widely used photographic medium until the gelatin dry plate was introduced in the 1870 s. The dry plate eventually replaced the wet plate, and photography became widely available. Photographic images were captured on glass negatives, which were used to make positive prints on albumen or salted paper.

A camera was imported by a Dutch ship going to Japan in 1848 (Wikipedia, 2020b). In China, the first photograph captured dates back to the early $19^{\text {th }}$ century with the arrival of European photographers in Macao. In the 1850s, western photographers set up studios in the coastal port cities, but soon their Chinese assistants and local competition spread to all regions. By the end of the $19^{\text {th }}$ century, all major cities had photographic studios where middle-class Chinese people could have portraits taken for family occasions (Wikipedia, 2020c and Peabody Museum, 2020). In contrast, the practice of photography in Korea was delayed until the late $19^{\text {th }}$ century because the Joseon Dynasty had a policy that forbids their citizens to make contact with foreigners. A few foreign photographers captured photographs in Korea or photographs of Korean people outside of Korea in the 1860s and 1870s. The history of photography in Korea spans approximately 150 years (Wikipedia, 2020d).

\subsection{Selection of photographs}

For meaningful digital photographic image comparisons from the viewpoints of data integrity, file fixity, characterization, sustainability, and renderability of well-known and widely introduced historic photographs with traceable information on the photograph's year and place of origin would be ideal candidates. The photographs of $\mathrm{Yu}$ Kil-Chun (1856-1914) who was an intellectual, writer, politician and independence activist of Korea's late Joseon Dynasty (Wikipedia, 2020e) seemed to be an ideal candidate for this study. He is well known as the first Korean student to study in Japan and the United States, and his activities were well documented and traceable.

In 1881, he went to Meiji Japan, as a member of a Korean 
mission and stayed in Japan to study at Keio University. He studied modernization from Fukuzawa Yukichi for a year. In 1884, he traveled to the United States as part of the first official Korean delegation to observe the American industry and government. After completion of the diplomatic mission, he studied at the Governor Dummer Academy in Byfield, Massachusetts, USA (Boston University, 2020). At the time, he was 27 years old. Even though he planned to study for five years in the United States, the political situation in Korea forced him to suddenly return to Korea. Once he decided to go back to Korea, he took the European route instead of crossing the Pacific Ocean. From Boston, he went to Japan via London, passing through the Suez Canal. This route helped him travel to diverse countries and see many new things. He left many photographs of his own and with other group members of the Korean mission to the United States in 1883. These are 137-year-old photographs with familiarity and are a perfect fit for this study. His life and activities have been taught in all Korean schools and are reported very widely with historic photographs, documents, and books. Thus, portraits of $\mathrm{Yu}$ Kil-Chun and his group photographs were used for digital image comparisons.

Figure 1 shows six portraits of Yu Kil-Chun downloaded from various Internet archives. All portraits seemed to be drawn from the same photograph even though Figure $1(\mathrm{~F})$ is a mirror image of the others. The original one is believed to have been photographed in the $1880 \mathrm{~s}$. All images have their own sizes, shapes, and tones, and identifying the original photo from visual inspection is difficult. Even though one can have his/her feelings or opinions, providing a rational explanation for it is difficult. Quantitative colorimetric analysis and dimension analysis can provide rationale for the opinion-forming process. Group photographs of Yu Kil-Chun are used in the discussion section.

Figure 1 (E) was described as a photograph taken while he was studying in Japan in 1882 (Wikipedia (Korean Language), 2020g). According to the New York Times in November 1983, he cut his hair while he was visiting his host Prof. Edward Morse (Director of Peabody Essex Museum) in Salem, Massachusetts (Medical Observer, 2013). His name was spelled as 'Yu Chil Chun' in a New York Times article. Thus, the authors also believe that this portrait was photographed while he was staying in Massachusetts in 1893 or 1894

\subsection{Image analysis software}

There are several commercial image viewing and editing software products available for general users as well as application-specific image editing software for professionals. However, finding handy image processing software designed for detailed image analysis, including statistical colorimetric analysis, dimensional measurement, image comparison, outline detection, and color selection with image/numerical data export for digital forensic and conservation science applications, is difficult. PicMan (WaferMasters, Inc., CA,
(A)

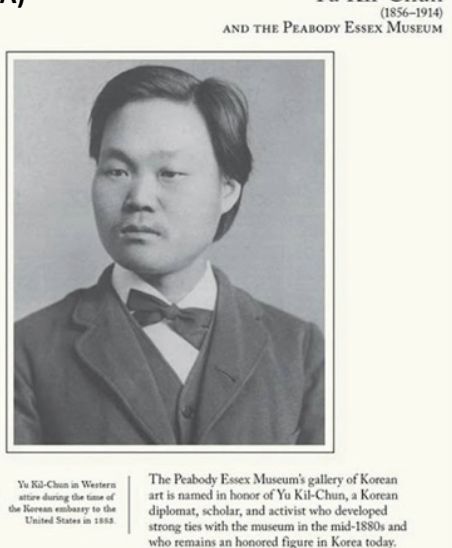

(B)
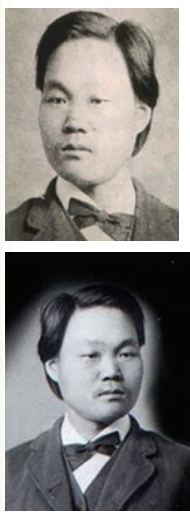

(C)

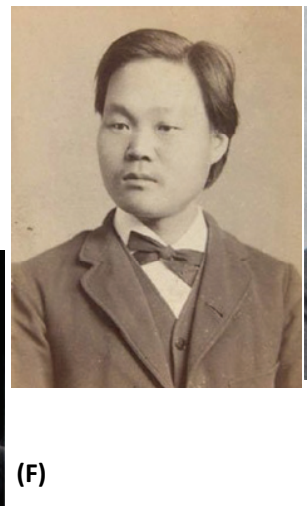

(D)

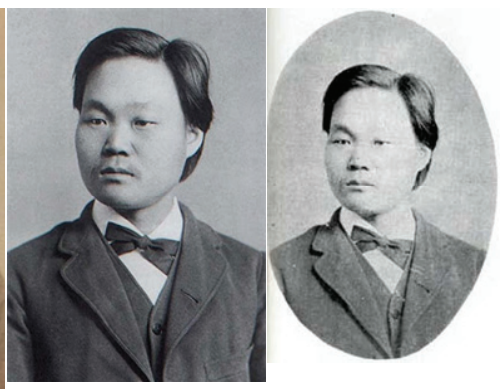

Figure 1. Portraits of Yu Kil-Chun downloaded from various web archives. (Sources: (A) Boston Korean Society 2020, (B) Joong Ang Daily, 2007, (C) Joong Ang Daily, 2009, (D) Boston University, 2020, (E) Wikipedia (Korean Language), 2020g, and (F) Jung Do Ilbo, 2016). 
USA) is a novel image processing/analysis software package, originally developed for scientific and engineering applications and was subsequently customized for conservation science applications. Statistical colorimetric analysis, image comparison, image highlight, and digital forensic functions were enhanced for this study.

A few application examples of image analysis software (PicMan) have been previously reported (Yoo et al., 2017; Yoo et al., 2019; Kim et al., 2019; Yoo et al., 2020b; Yoo and Yoo, 2020; Ryu et al., 2020). As all images are either digitally generated ("born- digital") or transformed to digital images via scanning or photography, having quantitative image analysis and comparison capabilities is becoming increasingly important for record keeping (archiving) and reference establishment for evaluation of aging-related changes and restoration of cultural heritages. It can also be used to investigate imitations and forgeries in various fields. The original position of mythical stone lion statues in front of the Gwanghwamun gate in Seoul was also estimated by using analytical photogrammetry, which is an application using image analysis (Nam et al., 2020a; Nam et al., 2020b). Colorimetric determination techniques used in medical and pharmaceutical applications have been reported (Yoo et al., 2020a). They are derivative applications of the image analysis technique used in PicMan.

\section{RESULTS}

Five portraits of $\mathrm{Yu}$ Kil-Chun in different sizes and colors (from Figure 1) were selected for image comparison and analysis. The horizontally flipped portrait (Figure 1 (F)) was excluded owing to the artificial modification (mirroring) of the original portrait. Figure 2 shows five portraits of $\mathrm{Yu}$ Kil-Chun after face size adjustment, grayscale conversion of selected area (face), and highlighted 8-level color contour maps corresponding to the brightness level. The face size was adjusted to the face size of image A of Figure 1 [144 pixels in width and 183 pixels in height $($ area $=144$ pixels $\times 183$ pixels $=26,352$ pixels)]. If the aspect ratio of the face in any portrait does not match with image A of Figure 1, the face size (from the lower jaw to the top of the hair) was adjusted to a height of 183 pixels without changing the aspect ratio during size adjustment. All five images seemed to be derivatives of the same image. However, the aspect ratio of the second image from the left was different from that of the rest. It seemed to be vertically stretched, which may be intentional or reckless alteration.

The color difference between portraits may be owing to different reasons. If we were comparing printed photographs with color variations, we may consider age-related color fading as a potential cause. However, all portraits were downloaded from digital archives and aging did not cause color fading owing to the nature of the digital image. The color variation between portraits must be due to intentional color adjustment and/or color shift during digitization by scanning or photographing a printed image. To compare the face area without bias, the face areas of all portraits were converted to grayscale images (Figure 2B). The subtle differences in brightness and contrast levels between faces can be noticed. The grayscale images were expressed in 8-bit $\left(2^{8}=256\right)$ brightness levels. To highlight the subtle differences in brightness and contrast levels in grayscale images, 8-bit brightness levels were simplified to 3-bit $\left(2^{3}\right.$ $=8$ ) brightness levels and color-coded. As seen in Figure 2 (C), we can easily recognize the difference in brightness levels used in each portrait by observing the background color and number of colors on the hair and the face. In terms of brightness levels, the fourth image from the left has the most detailed information, and the fifth image from the left shows the lowest level of detail, in terms of brightness levels. Qualitative visual inspection is still subject to personal feelings or the sensitivity of individuals. Quantitative means of image characterization must be introduced to make numerical data-based objective judgments.

A digital image is composed of pixels. All pixels have color (brightness of red (R), green $(\mathrm{G})$, and blue (B) channels) and its coordinate information. A unique combination of color and coordinate information of individual pixels forms a characteristic image. We can gather color and coordinate information from every pixel on the image and analyze it numerically using statistical analysis.

Figure 3 shows a screen-captured image of the image processing/analysis software (PicMan). The five portraits of $\mathrm{Yu}$ Kil-Chun used in Figure 2 (A) were opened to demonstrate color and coordinate information extraction from selected points (pixels), lines, and areas. For point measurement, five points on the head of portraits (one point per portrait) were selected, and their color information was 
(A)
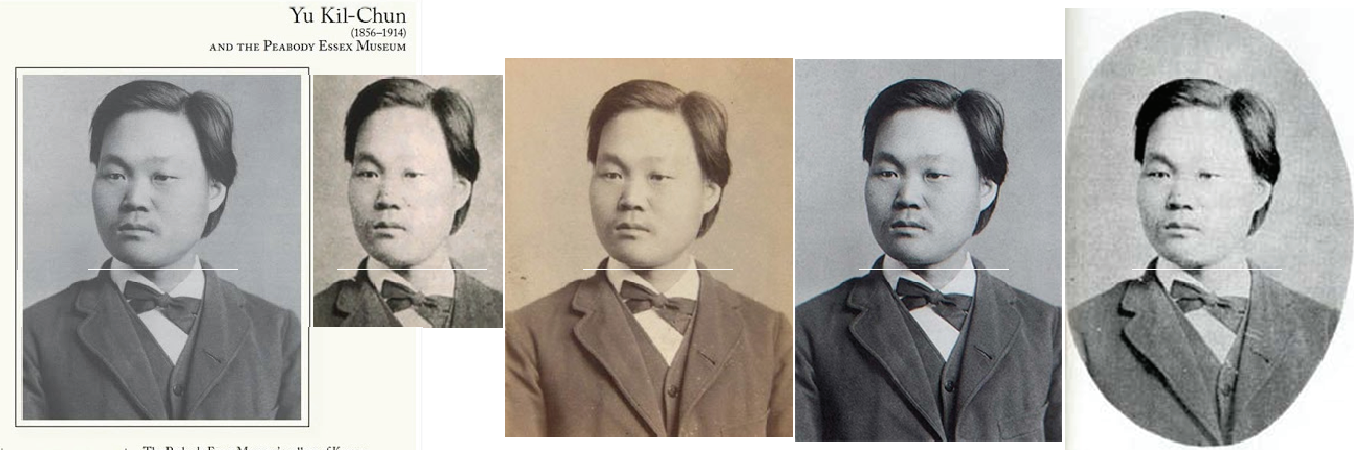

(B)
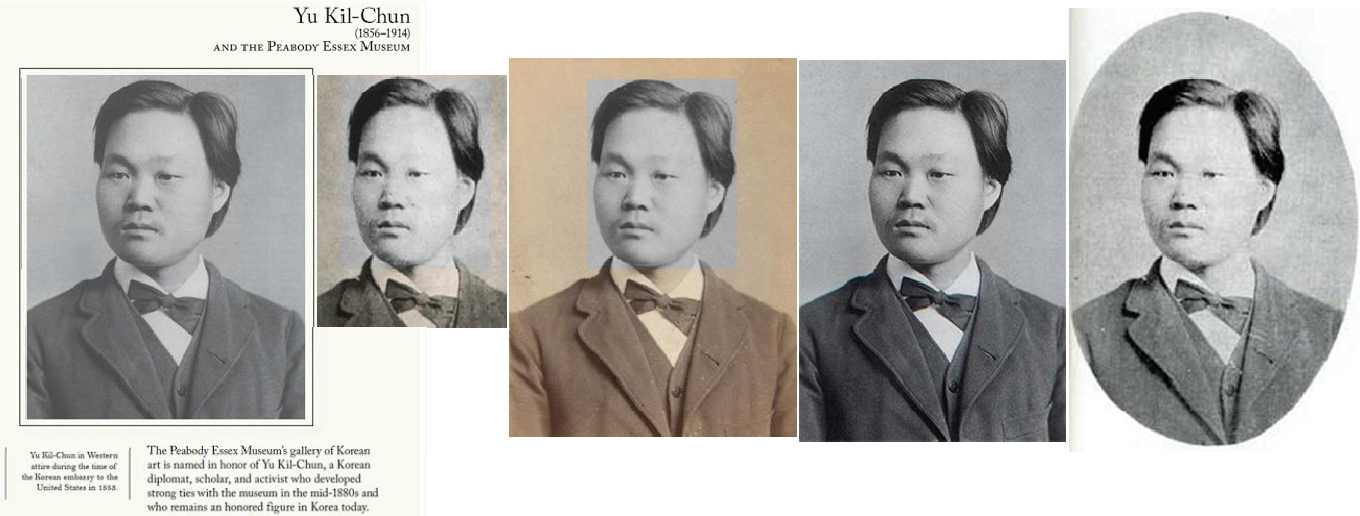

(C)
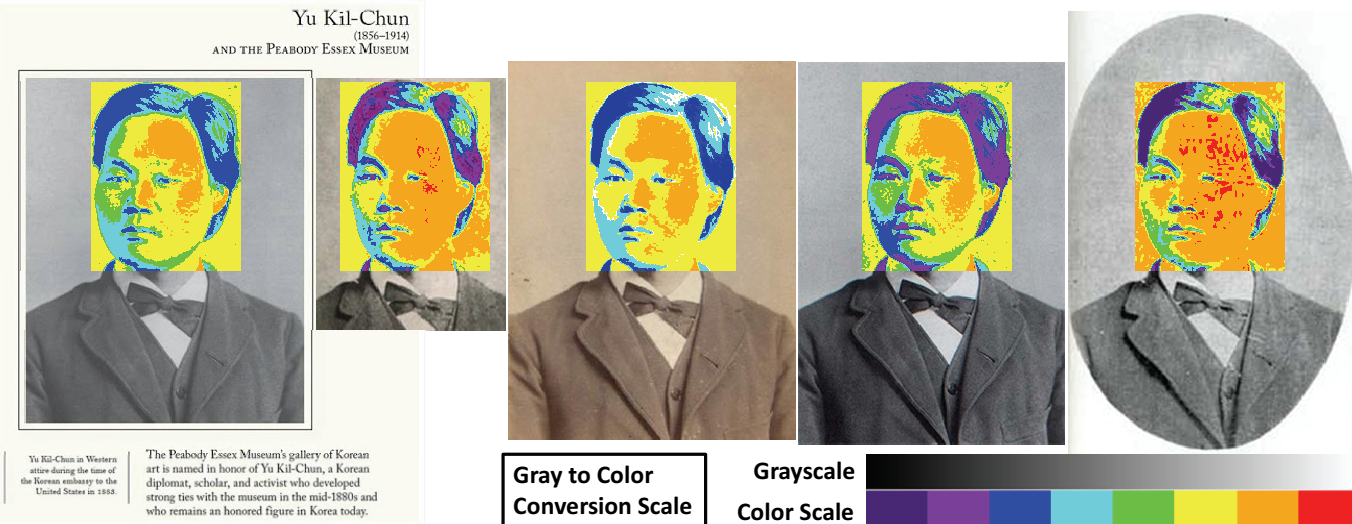

Grayscale

Color Scale

Figure 2. Five portraits of Yu Kil-Chun. (A) After face size adjustment, (B) After grayscale conversion, and (C) As 8-level digitized color contour maps.

extracted (RGB intensity, hue, saturation, and value) and hexadecimal color codes (or HTML color codes or web colors) used in color monitors. $\mathrm{L}^{*} \mathrm{a}^{*} \mathrm{~b}^{*}$ and Munsell color code can also be extracted. The color information on a line can be displayed as RGB, and its average intensity graph is shown on top of the screen-captured image. The RGB intensity is plotted with its own color line, and the average intensity is plotted with a gray line. The intensity range displayed in the figure ranges from 0 to $255\left(2^{8}=256\right.$ levels $)$. A grayscale image has the exact same intensity for each channel $(R=G=B)$. Images close to grayscale will show multiple lines for RGB and average intensity (gray line) next to each other. Images with color will show distinctive RGB and gray intensity lines, as shown in the middle portrait. By 


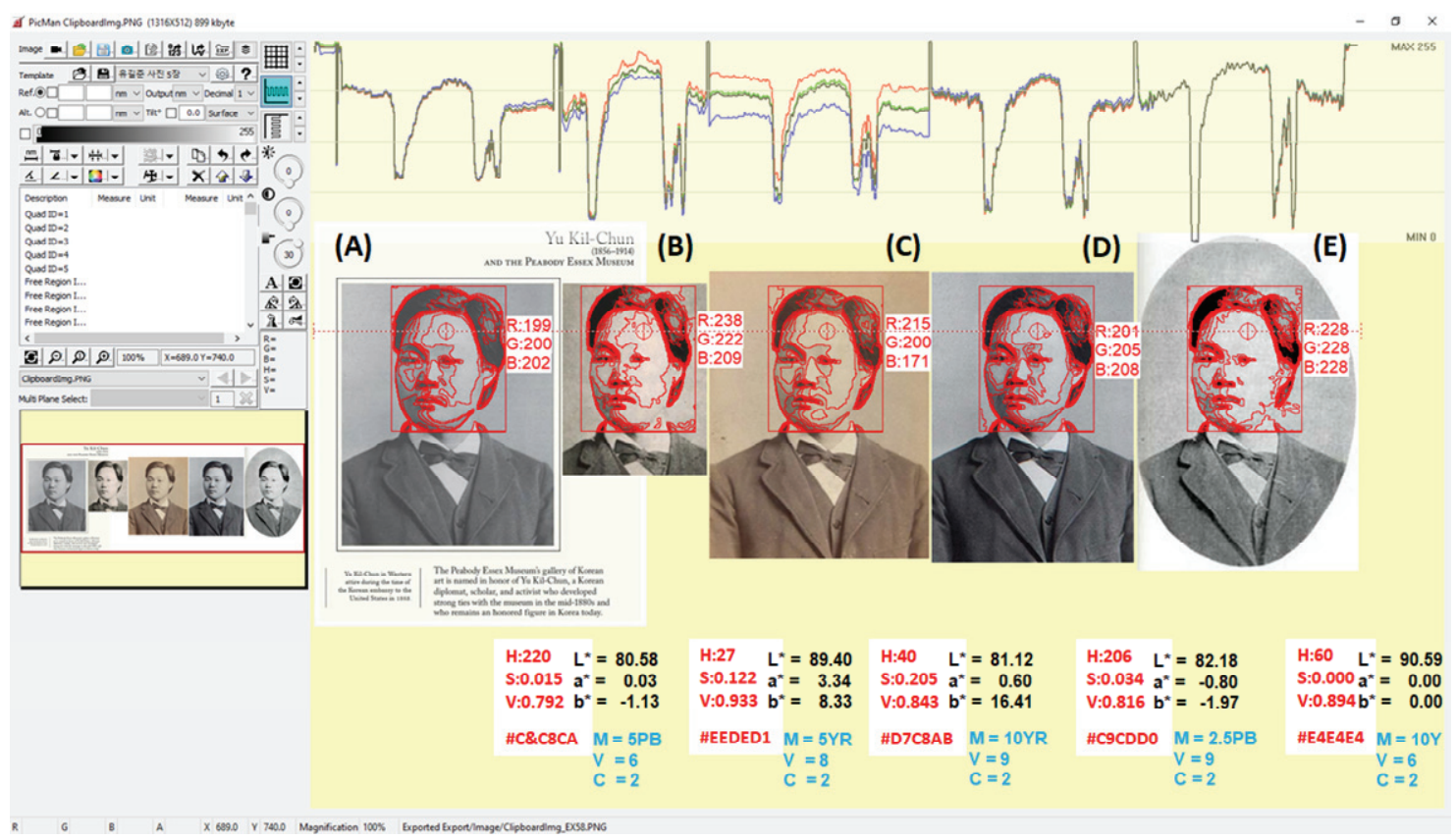

Figure 3. Screen-capture image of the image processing/analysis software (PicMan) demonstrating numerical analysis of colors at points, on lines and in areas. RGB, HSV, L*a*b*, hex color code and Munsell color at the points are shown. Contour lines within selected areas were superimposed on the portraits.

observing the line intensity graph, one can make an objective judgment rather than an instinctive one on the origin of the color differences among portraits of the same posture. Even for the middle portrait, RGB and gray lines showed similar trends with the intensity shifts across the portrait. It is almost a monotonic image of the same color. It is not only an instinct-based visual judgment but also is supported by numerical, data-based objective judgment.

The dataset for the intensity graph can be exported as a comma-separated value (CSV) file for additional numerical analysis and customized graph generation. HSV, $\mathrm{L}^{*} \mathrm{a}^{*} \mathrm{~b}^{*}$, and Munsell color information are also exported in the CSV file. Three 8-bit channels of RGB make 24 bits per image ( 8 bit/channel $\times 3$ channels $=24$ bits). A 24-bit image can be expressed from black to white $\left(2^{8} \times 2^{8} \times 2^{8}=2^{24}=\right.$ $16,777,216$ tones of color). The color information on multiple lines can also be exported as either one CSV file per line or one CSV file for all lines.

Ten (10)-level contour lines were superimposed on the face of the portraits. As demonstrated with point and line data, the color and coordinate information of all pixels in selected area (s) (face surrounding rectangular area (s)) can be extracted as a statistical summary with frequency (occurrence) information per channel for histogram generation.

Figure 4 shows the RGB intensity histograms of each portrait before grayscale conversion (five portraits in Figure 2 (A)). The color information for 26,352 pixels per rectangle covering the face area was plotted as a function of the RGB intensity interval of 1 (Figure 4). They are histograms of 26,352 pixels per rectangle on each portrait. The histogram information of colors can provide additional insights into the image quality and potential alteration history.

Portraits B and C showed shifts between RGB histogram curves, indicating the presence of color components, while portraits A, D, and E are close to grayscale images. Portrait A only utilized a very narrow range of intensity values. As a result, it has a shallow depth of contrast. Portrait D utilized a broader intensity range and showed more depth of contrast. On the contrary, portrait E has simple RGB peaks centered at an intensity value of approximately 215 , implying that the details of the original image have been lost. The origin of the colors of portraits $\mathrm{B}$ and $\mathrm{C}$ should be answered as to whether it was from the original image or altered. The other grayscale images such as portraits of $\mathrm{A}, \mathrm{D}$, and $\mathrm{E}$ also face the same question: How close are the apparent color (nearly 

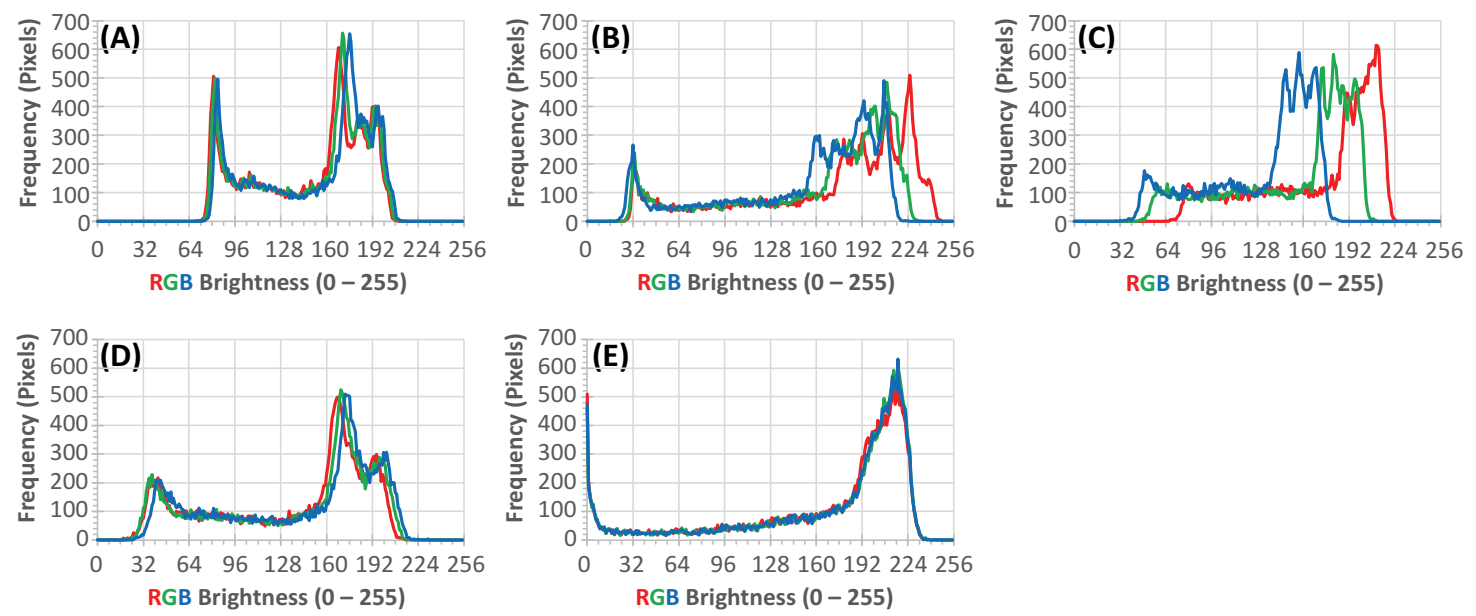

Figure 4. Histograms of color information for 26,352 pixels per rectangle are plotted as a function of RGB intensity interval of 1.

Table 1. Attribute information of rectangular areas and their aging average intensity statistics on individual portraits

\begin{tabular}{lrrrrr}
\hline & \multicolumn{5}{c}{ Portrait } \\
\hline & \multicolumn{1}{c}{ A } & \multicolumn{1}{c}{ B } & \multicolumn{1}{c}{ C } & \multicolumn{1}{c}{ D } & \multicolumn{1}{c}{ E } \\
Width (pixels) & 144 & 144 & 144 & 144 & 144 \\
Height (pixels) & 183 & 183 & 183 & 183 & 183 \\
Area (pixels) & 26,352 & 26,352 & 26,352 & 26,352 & 26,352 \\
Average Intensity (RGB Average) & 149.6 & 160.0 & 152.4 & 137.7 & 168.3 \\
Minimum Intensity & 69 & 23 & 47 & 2 & 0 \\
Maximum Intensity & 213 & 234 & 207 & 228 & 246 \\
Intensity Range & 144 & 211 & 160 & 226 & 246 \\
Intensity Standard Deviation & 39.7 & 56.8 & 41.6 & 55.3 & 64.1 \\
\hline
\end{tabular}

gray) and the depth of contrast to the original image? Without having the original image for comparison, we need clues from the individual portraits and circumstantial evidence to answer those questions. This is detective work similar to digital forensic investigation. Numerical data analysis plays a crucial role in scientific assessment and obtaining consensus from others.

Based on the histogram data shown in Figure 4, all five portraits show very different distributions of RGB intensity. Even if we were able to identify the original portrait, we may reach a conclusion that the other four, or all five, portraits may have been altered from the original portrait image. Data integrity and fixity may have been compromised and pose a big question.

The attribute information of rectangular areas on individual portraits and their statistics on RGB average (grayscale) intensity (brightness) of histograms in Figure 4 are summarized in Table 1. Quantitative, numerical data-driven image comparison becomes possible with the statistical information on the identical region of interest for different portraits. For colorimetric comparisons, statistics on RGB, HSV, and/or L*a*b* individual values are necessary. Tables 2 and 3 summarize the statistics of RGB and L*a*b* individual values of all pixels in rectangular areas on the portraits. The standard RGB (sRGB) values of individual pixels were converted to $\mathrm{XYZ}$ color space, and the converted $\mathrm{XYZ}$ values were converted to CIE $\mathrm{L}^{*} \mathrm{a}^{*} \mathrm{~b}^{*}$ values. Color conversion is a complex task because the color spaces in different color systems are defined differently. Few examples of color conversion formulas and procedures among color 
Table 2. Statistical colorimetric summary for RGB channels of all pixels in rectangular areas on individual portraits

\begin{tabular}{|c|c|c|c|c|c|c|c|c|c|c|c|c|c|c|c|}
\hline \multirow[b]{3}{*}{ Intensity } & \multicolumn{15}{|c|}{ Portrait } \\
\hline & \multicolumn{3}{|c|}{ A } & \multicolumn{3}{|c|}{ B } & \multicolumn{3}{|c|}{$\mathrm{C}$} & \multicolumn{3}{|c|}{ D } & \multicolumn{3}{|c|}{$\mathbf{E}$} \\
\hline & $\mathbf{R}$ & G & B & $\mathbf{R}$ & G & B & $\mathbf{R}$ & G & B & $\mathbf{R}$ & G & B & $\mathbf{R}$ & G & B \\
\hline Average & 148.2 & 149.7 & 152.2 & 169.4 & 160.6 & 150.9 & 172.6 & 153.8 & 131.1 & 135.6 & 137.7 & 141.5 & 167.3 & 167.3 & 167.3 \\
\hline Minimum & 68 & 69 & 71 & 27 & 23 & 16 & 64 & 45 & 29 & 5 & 3 & 0 & 0 & 0 & 0 \\
\hline Maximum & 212 & 213 & 215 & 247 & 233 & 224 & 225 & 211 & 186 & 223 & 227 & 238 & 246 & 246 & 246 \\
\hline Range & 144 & 144 & 144 & 220 & 210 & 208 & 161 & 166 & 157 & 218 & 224 & 238 & 246 & 246 & 246 \\
\hline Std. Dev. & 39.6 & 39.7 & 39.9 & 59.8 & 56.2 & 54.9 & 42.0 & 43.4 & 38.1 & 54.6 & 55.9 & 55.2 & 64.2 & 64.2 & 64.2 \\
\hline
\end{tabular}

Table 3. Statistical colorimetric summary for $L^{*} a^{*} b^{*}$ of all pixels in rectangular areas on individual portraits

\begin{tabular}{|c|c|c|c|c|c|c|c|c|c|c|c|c|c|c|c|}
\hline \multirow[b]{3}{*}{ Index } & \multicolumn{15}{|c|}{ Portrait } \\
\hline & \multicolumn{3}{|c|}{$\mathbf{A}$} & \multicolumn{3}{|c|}{ B } & \multicolumn{3}{|c|}{$\mathbf{C}$} & \multicolumn{3}{|c|}{ D } & \multicolumn{3}{|c|}{$\mathbf{E}$} \\
\hline & $\mathbf{L}^{*}$ & $a^{*}$ & $\mathbf{b}^{*}$ & $\mathbf{L}^{*}$ & $a^{*}$ & $\mathbf{b}^{*}$ & $\mathbf{L}^{*}$ & $a^{*}$ & $\mathbf{b}^{*}$ & $\mathbf{L}^{*}$ & $a^{*}$ & $\mathbf{b}^{*}$ & $\mathbf{L}^{*}$ & $a^{*}$ & $\mathbf{b}^{*}$ \\
\hline Average & 61.51 & -0.5 & -1.52 & 65.72 & 1.41 & 6.23 & 64.14 & 3.42 & 14.46 & 56.39 & 0.10 & -2.37 & 68.19 & -0.84 & 0.01 \\
\hline Minimum & 29.26 & -2.67 & -4.24 & 8.36 & -4.03 & -2.14 & 20.65 & -1.17 & 4.29 & 0.88 & -10.13 & -19.32 & 0 & -2.90 & -2.82 \\
\hline Maximum & 85.25 & 1.93 & 0.31 & 93.12 & 7.47 & 11.40 & 84.86 & 11.15 & 24.24 & 90.15 & 14.06 & 9.55 & 96.88 & 0.68 & 1.63 \\
\hline Range & 55.99 & 4.60 & 4.55 & 84.76 & 11.50 & 13.54 & 64.21 & 12.32 & 19.95 & 89.27 & 24.19 & 28.87 & 96.88 & 3.57 & 4.45 \\
\hline Std. Dev. & 15.40 & 0.40 & 0.69 & 22.48 & 1.65 & 1.59 & 16.58 & 2.24 & 2.96 & 22.30 & 1.75 & 1.97 & 25.50 & 0.79 & 0.14 \\
\hline
\end{tabular}

spaces can be found in EasyRGB 2020 and Wikipedia 2020h.

With graphical expressions in Figures 2 and 3, the numerical information, including statistics summarized in Tables 1-3, provide in-depth understanding of individual images and lead logical questions toward problem solving.

\section{DISCUSSION}

Two identical group photographs of Joseon's first diplomatic delegation to the United States were selected for image comparison and investigation of the possible cause of color differences between them (Figure 5). According to the record, the group photo was captured in September 1893 after arriving in the United States (Monthly Chosun, 2016 and University of Wisconsin Milwaukee, 2020). As of today, these photographs are 137 years old. The photograph on the top (Figure $5(\mathrm{~A})$ ) is black and white, and the other photograph, on the bottom (Figure 5 (B)), is brownish. Can we identify which photo is the original with supporting evidence? From our instinct, the brownish-colored photo seemed to be the original. There are many elements of circumstantial evidence: brownish color by aging, larger field of view, hand-written memos, natural color change of paper, and institutional ownership of the photo. However, we have to ask ourselves how confident are we? and whether our assumption supported by data? The top black and white photograph looks much clearer and vivid. We need to employ numerical, data-driven investigation.

To gather numerical data from the two photographs, a vertical line was drawn at the same location of the two photographs. Line intensity graphs were generated using PicMan along the vertical lines (left). The top photo only shows black line graphs, indicating that it is a perfect grayscale image $(R=G=B)$. Unless it is not a 'born digital' image, creating a perfect grayscale image by scanning or photographing it is not possible. The top image must have been altered after scanning, photographing, or downloading.

The bottom photograph, however, shows shifted RGB line graphs, and an average line graph overlaps with a green line graph. The red line graph shows higher brightness and the blue line graph shows lower brightness compared to the green line graph. The trends are the same for both photos and paper. The difference in intensity ratio among RGB on photo and paper is quite different. The red channel did not saturate 


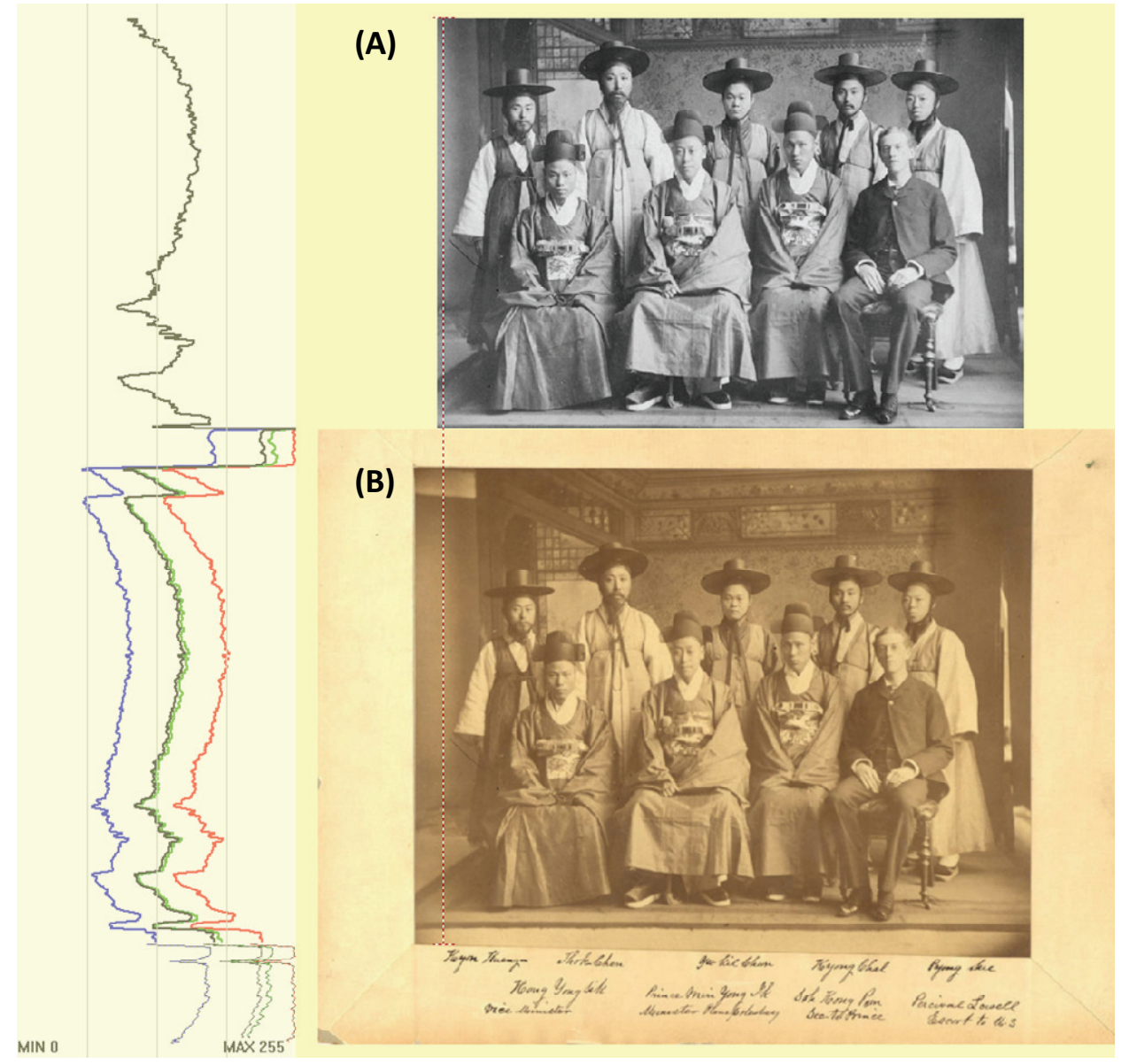

Figure 5. An official commemorative photo taken by Joseon's first diplomatic envoy after arriving in the United States in September 1883. (Yu Kil-Chun: the middle of second row) Intensity profiles along the red dotted vertical line on the two photographs are shown.

on the photo but did so on the surrounding paper due to aging. The ratio of RGB intensity (or magnitude of shift) is proportional to the green channel intensity (or average intensity) on the photo. The same trend was observed in Figure 3 (C) and Figure 5 (B). There must be reasons for this phenomenon.

It is easy to form an opinion without supporting data, which can lead to the formation of a biased opinion. We have our own experience on the color change of white paper or books into brownish color due to light damage and oxidation. Owing to this, we tend to believe that a brownish color is a sign of a vintage photo without deep consideration. When we see an old picture of brown color taken in the 19th century, we are often confused whether the original was in color or black and white.
We must consider techniques and materials used in early photography in the $19^{\text {th }}$ century. Most photographs captured during that period are "salt prints" or "albumen prints," which provide warm brown tones. Old photographs that we see in museums or antique shops are quite the same as they looked immediately after printing. Salt prints have very strong archival durability and can last for more than one hundred years if cared for properly, as we observed in the example photographs herein. All photographs were monotone back then, as opposed to color, and even black and white. This is because the printing materials were not capable of true blacks (Cargill, 2020).

The brown color we see from the $19^{\text {th }}$ century samples is sepia, which is considered a form of black and white or monochromatic photography. The appearance is called sepia 
toned (Heritage Photo Restoration, 2020). Sepia toning became the preferred method for developing photographs until the 1920s. It became obsolete by 1930 due to the introduction of new technology and materials. Understanding the historical aspects of photography technology and materials is as important as following new technology.

Based on the RGB intensity (red, green, and blue lines) compared to grayscale-converted intensity (gray line) of pixels on the dotted red vertical line in the sepia-toned group photography (Figure 5 (B)), the sepia-toned photograph shows demonstrates characteristic features of enhanced red color and suppressed blue color, while the green color component represents the average of RGB intensity values. Thus, the enhanced red color and reduced blue color in Figures 3 (C) and 4 (C) showed the best matched characteristics of sepia-toned photographs, as seen in Figure 5 (B). All other images were altered versions of photographs in color, brightness, contrast, aspect ratio, and/or mirroring from the original photograph. Quantitative color and intensity analysis data for all pixels in the rectangular areas on individual portraits in Figure 2 (A) indicate the statistical differences in RGB and $\mathrm{L}^{*} \mathrm{a} \mathrm{b}^{*}$ values between images with various combinations of image alterations.

In digital photography, toning can be simulated digitally, either in-camera or in post-processing, to make special effects. Data can be easily altered and/or changed intentionally, or by mistake. The identification and description of digital materials must be available. Longevity of digital information and accessibility are also important for practical applications. Data integrity, file fixity, characterization, sustainability, renderability, and related issues of photographic images, as mentioned above, must be addressed for conservation science applications in an effective and reliable manner. Preservation of physical copies and context (interconnections between data and between documents) is crucial for data integrity and file fixity, from both archiving and conservation science viewpoints.

\section{CONCLUSIONS}

Internet accessibility in the digital era has made information search, including image search from large archives of information, easier and affordable at any time, from anywhere, even from remote locations. Information transmission and sharing can be instantly performed at very high data rates at any time. In the case of images, there are risks of transmitting and sharing true images and either recklessly or intentionally alter images. The alteration of images can occur at any stage, and the altered images can also be transmitted and used as an additional source of information by followers, without knowing or suspecting data integrity and fixity compromises.

In this study, 137-year-old historical portraits and group photographs of $\mathrm{Yu}$ Kil-Chun were compared to investigate the aging effects and artificial modifications using image processing software. Statistics of red (R), green (G), blue (B), and $L^{*}, a^{*}$, and $b^{*}$ values of every pixel in the selected identical areas of portraits were compared. The possible causes of variations between images, including aging effects and artificial modifications, were investigated. We have identified that sepia toning used in black and white photographs until the 1930s can cause confusion in identifying possible causes of variations between derivatives of an original image. Modern digital sepia toning can also add confusion with aging effects. The importance of preservation of physical copies and preservation of context (interconnections between data and between documents) is discussed and emphasized from the viewpoints of archiving and conservation science.

\section{REFERENCES}

Boston Korean Society, 2020, Yu Kil-Chun, http://www.bostonks.com/ (October 21, 2020)

Boston University, 2020, Yu Kil-Chun (1856-1914): A bridge-person of Korea to the west and the first Korean student in the United States. http://sites.bu.edu/ koreandiaspora/individuals/boston-in-the-1880s/yu-kil-chun1856-1914-a-bridge-person-of-korea-to-the-west-and-thefirst-korean-student-in-the-united-states/ (October 21, 2020)

Cargill, J., 2020, https://www.quora.com/When-I-see-an-oldpicture-of-brown-colour-taken-in-the-19th-century-wasthat-its-original-colour-or-black-and-white (October 21, 2020)

Digital Preservation Coalition, 2008, Preservation management of digital materials: The handbook, https://www.dpconline.org/ (October 21, 2020)

Easy RGB, http://www.easyrgb.com/en/math.php (November 27, 2020)

Evans, M. and Carter, L., 2008. The challenges of digital preservation. Presentation at the Library of Parliament, 
Ottawa, Canada.

Heritage Photo Restoration, 2020, What is sepia tone? https://www.photoancestry.com/what-is-sepia.html (October 21, 2020)

Joong Ang Daily, 2007, Yu Kil-Chun Yu, the first Korean to study in the US, https://news.joins.com/article/ 2854588 (October 21, 2020)

Joong Ang Daily, 2009, First international student $\mathrm{Yu}$ Kil-Chun's ${ }^{『}$ Seo Yu Gyeonmun $₫$ ), https://news.joins. com/article/2854588 (October 21, 2020)

Joongdo Ilbo, 2016, April 1: Yu Kil-Chun's way, http://m.joongdo.co.kr/view.php?key=2016033100000 5135 (October 21, 2020)

Kim, G., Kim, J.G., Kang K. and Yoo, W.S., 2019, Image-based quantitative analysis of foxing stains on old printed paper documents. Heritage, 2, 2665-2677, doi;10.3390/heritage2030164

Nam, H. H., Oh, H., Yu, B. J., Kim, J. G. and Kang, K., 2020a, Estimation of the original location of Haechi (Haetae) Statues using historical photographs and image analysis software, The $51^{\text {th }}$. $52^{\text {nd }}$ Conference of the Korean Society of Conservation Science for Cultural Heritage, Daejeon, Korea, October 16-17, 113-118.

Nam, H.H., Oh, H., Chung, H.K., Yoo, Y. and Yoo, W.S., $2020 \mathrm{~b}$, Reproduction of the same shooting composition as historical photographs for the estimation of the original location of Haechi (Haetae) Statues, The $51^{\text {th }}$. $52^{\text {nd }}$ Conference of the Korean Society of Conservation Science for Cultural Heritage, Daejeon, Korea, October 16-17, 151-156.

Medical Observer, 2013, At the time, the New York Times introduced 'Student, Yu Chil Chun', http://www.monews. co.kr/news/articleView.html?idxno=55473

Menne-Haritz, A., 2001, Access - the reformulation of an archival paradigm, Archival Science, 1, 57-82.

Merriam-Webster, 2020, archive. https://www.merriamwebster.com/dictionary/archive (October 21, 2020)

Monthly Chosun, 2016, Korean diplomatic history through person (22) Yu Kil-Chun Laying the theoretical basis for modernization reform, http://monthly.chosun.com/ (October 21, 2020)

Peabody Museum, 2020, History of photography in China, https://www.peabody.harvard.edu/node/2471 (October 21, 2020).

Ryu, S., Yoo, W.S. and Baba, H., 2020, Study on readability improvement of damaged wooden tablets using image processing software. The $51^{\text {th }} .52^{\text {nd }}$ Conference of the Korean Society of Conservation Science for Cultural Heritage, Daejeon, Korea, October 16-17, 301-302.

Sam Houston State Library, 2020, What is an archive? https://library.shsu.edu/ (October 21, 2020)

University of Wisconsin Milwaukee, 2020, South Korea, Prince Min Yong Ik, diplomats, and naval officer, https://collections.lib.uwm.edu/digital/collection/agsphoto /id/202/ (October 21, 2020)

Van Garderen, P., 2007, Archival materials: a practical definition, https://web.archive.org/ and https://vangarderen. net/ (October 21, 2020)

Wikipedia, 2020a, Photography, https://en.wikipedia.org/ wiki/Photography (October 21, 2020)

Wikipedia, 2020b, Photography in Japan, https:/en.wikipedia. org/wiki/Photography_in_Japan (October 21, 2020)

Wikipedia, 2020c, Photography in China, https:/en.wikipedia. org/wiki/Photography_in_China (October 21, 2020)

Wikipedia, 2020d, Photography in Korea, https://en.wikipedia. org/wiki/Photography_in_Korea (October 21, 2020)

Wikipedia, 2020e, Yu Kil-chun, https://en.wikipedia.org/ wiki/Yu_Kil-chun (October 21, 2020)

Wikipedia, 2020f, Digital Preservation, https://en.wikipedia. org/wiki/Digital_preservation (October 21, 2020)

Wikipedia (Korean Language), 2020g, Yu Chil Chun, https://ko.wikipedia.org/wiki/\%EC\%9C\%A0\%EA\%B8\% B8\%EC\%A4\%80\#/media/\%ED\%8C\%8C\%EC\%9D\%BC: Yukiljun-1882.jpg (October 21, 2020)

Wikipedia, 2020h, CIELAB color space, https://en.wikipedia. org/wiki/CIELAB_color_space (November 27, 2020)

Yoo, W.S.; Ishigaki, T. and Kang, K., 2017, Image processing software assisted quantitative analysis of various digital images in process monitoring, process control and material characterization, The 2017 International Conference on Frontiers of Characterization and Metrology for Nanoelectronics (ICFCMN), Monterey, CA, USA.

Yoo, W.S., Kang, K., Ishigaki, T., Kim, J.G. and Ishigaki, T., 2019, Image-based dimension analysis for semiconductor and MEMS structures, The 2019 International Conference on Frontiers of Characterization and Metrology for Nanoelectronics (ICFCMN), Monterey, CA, USA.

Yoo, W.S., Han, H.S., Kim, J.G., Kang, K., Jeon, H.S., Moon J.Y. and Park, H., 2020a, Development of tablet PC-based portable device for colorimetric determination of assays including COVID-19 and other pathogenic microorganisms. Royal Society of Chemistry Advances 10, 32946-32952: https://doi.org/10.1039/D0RA05866A

Yoo, W.S., Kim, J.G., Kang, K. and Yoo, Y., 2020b, Considerations of color expression methods for paper-based cultural properties in conservation science. The $51^{\text {th }} .52^{\text {nd }}$ Conference of the Korean Society of Conservation Science for Cultural Heritage, Daejeon, 
Korea, October 16-17, 306-311.

Yoo, Y. and Yoo, W.S., 2020, Quantification and description of colors and brightness of photographic images using image analysis software. The $51^{\text {th }} \cdot 52^{\text {nd }}$ Conference of the Korean Society of Conservation Science for Cultural Heritage, Daejeon, Korea, October 16-17, 303-305. 